EXATASE TECNOLÓGICAS

V.3 N.3 • Agosto/Setembro/Outubro - 2019

ISSN Digital: 2359-4942

ISSN Impresso: 2359-4934

DOI: $10.17564 / 2359-4942.2019 v 3 n 3$

\section{A PRESENCCA WEB DE UMA INSTITUIÇÃO EDUCATIVA}

THE WEB PRESENCE OF AN EDUCATIONAL INSTITUTION

LA PRESENCIA WEB DE UNA INSTITUCIÓN EDUCATIVA

Vitor Gonçalves ${ }^{1}$

Márcio Rogério Carvalho

Layse Santos Souza ${ }^{3}$

\section{RESUMO}

O objetivo deste trabalho foi descrever um projeto de disponibilização de plataforma e aplicações web online, em uma Instituição de Ensino Superior de Portugal, atendendo os requisitos de segurança. A metodologia adotada seguiu os princípios do Design Science Research, apresentando a solução para um problema identificado. Como resultados, se obteve que a reinstalação do servidor não só restabeleceu os níveis de segurança necessários, como também, permitiu a atualização para as versões mais recentes das plataformas open source utilizadas. Como principal desvantagem identificou-se a arquitetura física da máquina, uma vez que o equipamento não poderia ser atualizado.

\section{PALAVRAS-CHAVES}

Linguagem de programação. Servidor de banco de dados. Servidor web. 


\section{ABSTRACT}

The objective of this work was to describe a project to provide online platform and web applications in a Higher Education Institution in Portugal, meeting security requirements. The methodology adopted followed the principles of Design Science Research, presenting the solution to an identified problem. As a result, it founded that reinstalling the server not only restored the required security levels but also enabled the update to the latest versions of the open-source platforms used. As the main disadvantage, the physical architecture of the machine was identified, since the equipment could not be upgraded.

\section{KEYWORDS}

Database Server. Programming Language. Web Server.

\section{RESUMEN}

El objetivo de este estudio fue describir una plataforma que proporciona el diseño web y aplicaciones en línea, en una Institución de Educación Superior en Portugal, cumplir con los requisitos de seguridad. La metodología adoptada siguió los principios del Diseño Science Research, presentando la solución a un problema identificado. Como resultados, se obtuvo que la reinstalación del servidor no solo restableció los niveles de seguridad necesarios, como también, permitió la actualización a las versiones más recientes de las plataformas open source utilizadas. Como principal desventaja se identificó la arquitectura física de la máquina, ya que el equipo no podía ser actualizado.

\section{PALABRAS CLAVES}

Lenguaje de programación. Servidor de base de datos. Servidor web. 


\section{INTRODUÇãO}

Cogita-se, com muita frequência, a presença da web nas Instituições de Ensino Superior (IES) com relação ao uso das Tecnologias de Informação e Comunicação (TIC) devido às facilidades e inovações dos serviços oferecidos para a proliferação do saber entre discentes, docentes e instituições (JUNIOR; COUTINHO; ALEXANDRE, 2006).

Nesse contexto, o Núcleo de Administração e Desenvolvimento de Aplicações do Serviço de Tecnologias de Informação e Comunicação (NADA/STIC) visa desenvolver e administrar soluções informáticas que permitem impulsionar o uso de tecnologias educativas na Escola Superior de Educação de um Instituto Politécnico de Portugal. Entre as competências dessa unidade destacam-se a gestão das aplicações web, gestão de salas, equipamentos, POS reprografia, atualização da página web e dos sistemas de gestão de eventos e cursos de línguas, apoio técnico à comunidade acadêmica e administração dos servidores da escola (WWW, FTP, SGBD) como instalação, configuração e gestão de sistemas de e-learning e outros ambientes de aprendizagem.

A uniformização do sistema de e-learning e e-research da instituição, baseado no ambiente Sakai (https:/sakayproject.org), implicou a diminuição do cuidado na manutenção do servidor, o qual baseava-se na solução XAMPP para Windows o que favorecia a vulnerabilidade do sistema. O Centro de Comunicações (CCOM) da instituição recebeu um alerta da Rede Ciência, Tecnologia e Sociedade (RCTS)/ Centro de Estudos para Resposta e Tratamento de Incidentes em Computadores (CERT), indicando a vulnerabilidade de vários IP's na rede da escola, especificamente no protocolo SSLV2 (CVE-2016-0800).

Tal vulnerabilidade foi assumida como problema prioritário, pois permitiria que um atacante pudesse interceptar dados em comunicações cifradas, viabilizando que este tivesse acesso a informação sensível e privada, sempre que a chave privada do servidor estivesse sendo utilizada por qualquer serviço que suportasse SSLv2. Dessa forma, a equipe do NADA/STIC desenvolveu um projeto de recuperação do servidor de aplicações de forma a reinstalá-lo e garantir os níveis de segurança necessários. A descrição das fases dessa ação, objetivo do presente artigo, assume a metodologia Design Science Research, que tem como foco a solução para problemas existentes (DESCH; LACERDA; ANTUNES JÚNIOR, 2015).

A partir desta introdução, o trabalho apresenta a base teórica e metodologia utilizadas, prosseguindo para a exposição do projeto e desenvolvimento da solução. Por fim, são apresentadas as considerações sobre os resultados alcançados.

\section{FUNDAMENTAÇ̃̃O TEÓRICA}

Muito se discute a importância do uso da Web e das tecnologias para a propagação de conhecimento, comunicação e interação entre alunos, professores e instituições de ensino. Dessa forma, é indiscutível que essa nova forma de transmitir conhecimento pode ser um sistema eficiente que estabelece relações de segurança, correspondência e disseminação de sabedoria. 
Por esse motivo as IES por meio da Web conseguem oferecer seus cursos, ou somente alguns serviços de comunicação e objetos de aprendizagem digitais para esses cursos, no modo presencial e a distância a fim de conectar alunos, professores e instituições. Para disseminação do ensino e aprendizagem, as IES procuraram criar plataformas de aprendizagem para facilitar a comunicação, o acesso e o compartilhamento e um conjunto de informações e conteúdo, e.g., Ambientes Virtuais de Aprendizagem (AVA), Ambientes de Gestão de Aprendizagem (AGA), bibliotecas digitais e portais web (MAIA, 2003).

Esses novos sistemas de ensino e aprendizagem permitem a elaboração de novos meios para serem trabalhados e relacionados. De acordo com estudos nacionais e internacionais é evidente o interesse em explorar novos conceitos e soluções para criar novos paradigmas de ensino e aprendizagem (MORAIS et al., 2014).

\section{METODOLOGIA}

O presente trabalho abordou principalmente o uso da web nas IES no qual foi adotado o método de pesquisa Design Science Research por causa da necessidade de definir classes de problemas e artefatos para desenvolver conhecimento para elaboração de sistemas que ainda não existem ou precisam ser aprimorados, visando solucionar problemas baseados na sua relação teoria-prática.

Cada problema é único, inspira propostas e soluções ideais, pensamentos sistemáticos e informações limitadas a serviço de uma ação, assim prepara o direcionamento da pesquisa ao projeto de artefatos, mantendo as melhores soluções para os problemas existentes que geralmente são específicos, i.e., inviabilizando um conhecimento generalizado. À medida que ocorre a definição do problema, prático ou teórico, é necessário que exista uma conscientização com relação ao problema para que seja possível identificar os objetivos e metas necessários para que sejam solucionados satisfatoriamente.

Logo, essa união proporciona soluções não como meramente uma resposta concreta para determinado problema, mas como um conjunto de dados generalizados que são válidos para uma coleção de soluções para as classes de problemas. Tanto os problemas quanto às soluções podem partilhar características comuns que permitem a uma organização de conhecimento qualificada e generalizada geradas por meio das classes de problemas na área desejada (DESCH; LACERDA; ANTUNES JÚNIOR, 2015).

\section{PROJETO E DESENVOLVIMENTO DA SOLUÇ̄̃̃O}

Após o primeiro diagnóstico verificou-se a desatualização das versões das plataformas (SO Windows, Servidor de Base de Dados, Servidor Web, Web Framework PHP e Aplicações). Além dos problemas de segurança que esta situação implica também é possível perder desempenho e velocidade, logo, não ocorre o aproveitamento de novos plugins e de novas ferramentas de desempenho, funcionalidades e métricas. Em termos de características de hardware, destacam-se: nome servidor - WS-SERVER01, SO original - WINDOWS SERVER 200364 bits, idioma - PT-PT, IP -193.136.194.191, 
Processador - Intel XEON E5310 @ 1.6 Ghz, RAM - 4 GB, disco 1 (sistema): 250 GB. As características de software são apresentadas no resumo do Quadro 1.

Quadro 1 - Características de software do WS-SERVER01

\begin{tabular}{|c|c|}
\hline SOFTWARE & DESCRIÇÃO \\
\hline Apache & Apache/2.2 (Win32) / OpenSSL \\
\hline MySql & MYSQL 5.4 (X86_64) \\
\hline PHP & $\mathrm{PHP} / 5.2$ \\
\hline Antivírus & ESET SmartSecurity 4 \\
\hline \multicolumn{2}{|r|}{ Plataformas/Apps/Sites } \\
\hline $\begin{array}{l}\text { Eduser } \\
\text { Versão 2.0.0 }\end{array}$ & $\begin{array}{c}\text { OJS (OPEN JOURNAL SYSTEMS) - É uma publicação eletrônica, interdisciplinar } \\
\text { de carácter científico-divulgativo, dirigida a investigadores e profissionais da } \\
\text { educação. }\end{array}$ \\
\hline $\begin{array}{l}\text { AdolesCiência } \\
\text { Versão 2.0.0 }\end{array}$ & $\begin{array}{l}\text { OJS (OPEN JOURNAL SYSTEMS) - Revista da escola que está orientada para a } \\
\text { divulgação de reflexões e investigações realizadas por jovens do } 3^{0} \text { ciclo e secun- } \\
\text { dário ou estudantes dos cursos da instituição em coautoria com os mais novos, } \\
\text { que se encontrem a frequentar um estabelecimento de ensino não superior, } \\
\text { providenciando-lhes a oportunidade de expressarem as suas perspectivas de um } \\
\text { ponto de vista científico nas mais diversas áreas do conhecimento. }\end{array}$ \\
\hline $\begin{array}{l}\text { Moodle Easy- } \\
\text {-Learning } \\
\text { (Moodle 1.9) }\end{array}$ & $\begin{array}{l}\text { Easy-Learning é um sistema de e-Learning e b-Learning Moodle da Escola } \\
\text { Superior de Educação do Instituto Politécnico que visa complementar o Sistema } \\
\text { de e-Learning e de e-Research (IPB.virtual - http://virtual.ipb.pt) em situações } \\
\text { específicas, tais como: módulos ou ações de formação da Formação Contínua, } \\
\text { do Centro de Línguas, do Centro TIC e de outros programas ou projetos pontuais } \\
\text { da escola. }\end{array}$ \\
\hline phpWebQuest & $\begin{array}{l}\text { Plataforma que permite a criação e publicação de WebQuests, caças ao tesouro, } \\
\text { aventuras ou desafios na Web. }\end{array}$ \\
\hline Hotpotatoes & Website exemplificativo de tipo de exercícios concebidos no hotpotatoes. \\
\hline GFC & $\begin{array}{l}\text { Aplicação de Gestão de inscrições em cursos da Formação Contínua de profes- } \\
\text { sores. }\end{array}$ \\
\hline Gestão Eventos & Aplicação de Gestão de Eventos da Escola \\
\hline Outros sites & $\begin{array}{c}\text { Outros sites HTML de páginas web de aplicações simples e páginas web de } \\
\text { projetos. }\end{array}$ \\
\hline
\end{tabular}

Fonte: Elaborado pelos autores (2017). 


\subsection{INSTALAÇÃO E CONFIGURAÇ̃̃o}

Face à desatualização do sistema operacional e aplicações referidas, decidiu-se proceder à instalação completa do servidor, garantindo a migração dos dados das aplicações e dos utilizadores sempre que possível e desde que devidamente justificado.

As plataformas alojadas no servidor são dinâmicas, open source, que acessam bases de dados. Para isso, são empregados a linguagem de programação PHP e o Sistema Gerenciador de Banco de Dados MySQL. Essas tecnologias serão disponibilizadas em um servidor Apache HTTP, sob o Windows como sistema operacional. Cabe ressaltar que a instalação desses componentes ocorreu separadamente, em vez de utilizar-se uma solução integrada tipo XAMPP, WAMP, EasyPHP ou similar.

Em termos de hardware, decidiu-se substituir o disco de 250 GB por um disco de 250 GB SSD. Acrescentou-se, também, um disco para backups de 500 GB. Essa decisão justificou-se pelos ganhos em termos de acesso e escrita no disco. Em termos de atualização das características de hardware destacam-se nome servidor - WS-SERVER01, SO original - WINDOWS SERVER 2012 Standard R2 64 bits, idioma - PT-PT, Processador - Intel XEON E5310 @ 1.6 Ghz, RAM - 4 GB, disco 1 (sistema): 250GB SSD e disco 2 (backups): 500 GB.

Em termos de atualização das caraterísticas de software, tanto a versão mais recente do software de sistema (Windows Server 2012) quanto às versões estáveis mais recentes do software de servidor web (Apache, MySQL e PHP) e, ainda, as correspondentes plataformas referidas no Quadro 1 foram instalados no servidor atualizado Apache - Apache/2.4.18 (Win32)/OpenSSL/1.0.2g, MySQL 5.7.11 (X86_64), PHP 5.6.19, Antivírus - ESET SmartSecurity 4 com Firewall integrado. As plataformas/ Apps/Sites, referidas no Quadro 1, foram atualizadas para a versão estável disponível mais recente no primeiro semestre de 2017, período da realização do presente estudo.

4.1.1 Instalação e configuração do servidor WEB - APACHE

$\mathrm{Na}$ instalação do servidor web foi usado o Apache 2.4 VC11 Windows Binaries and Modules (Apache/2.4.18 - Win32 e OpenSSL/1.0.2g). O Apache Lounge HTTPD Server Project é fornecido pela Apache Software Foundation (ASF) por meio de ficheiros binários Windows e módulos populares "third-party". Também foi instalado o C++ Redistributable Visual Studio 2012 uma vez que era um dos pré-requisitos do servidor Apache.

Para instalar o Apache foi realizado o download do pacote de software e descompactaram-se os arquivos para uma pasta ServerRoot (e.g. Apache24). Descompacta a pasta para c:/Apache24 (ServerRoot) com o propósito de iniciar o serviço do Apache dentro do Console do DOS, digitou-se: httpd.exe. Para instalar o Apache como um serviço, deve-se digitar: httpd.exe -k install. Instalado o Apache 2.4, deve-se verificar se ele está funcionando. No Windows 2000/XP ele é instalado como um serviço que pode ser inicializado/desativado/reiniciado, usando o console de serviços, o "services.msc".

Por omissão, ele se configura para ser iniciado sempre junto com o Windows, mas pode alterar essa e outras opções de configuração. Ressalta-se que, ao fazer alterações no arquivo de configuração do Apache ou ao instalar um módulo, é sempre necessário reiniciar o servidor web, ou seja, o serviço do Apache, como ilustrado na Figura a seguir. 
Figura 1 - Apache Service Monitor

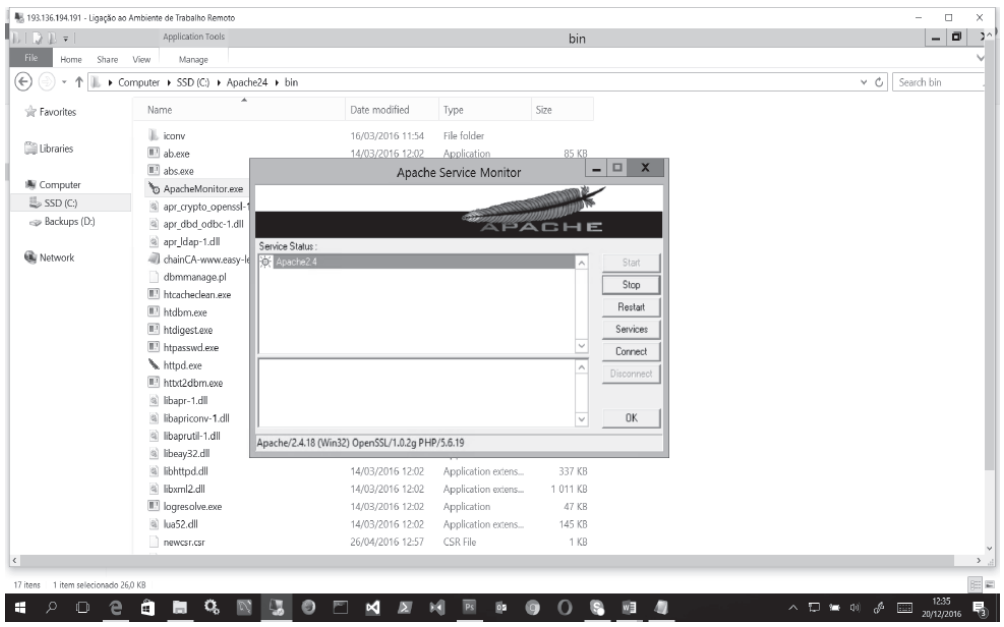

Fonte: Elaborado pelos autores (2017).

Após verificar que o serviço Apache está em execução, é necessário abrir um navegador ou browser e digitar o nome do computador ou o nome "localhost" referente ao computador local. Se preferir, o usuário pode acessar o IP da máquina local, i.e., http://127.0.0.1. Se tudo estiver correto, surgirá a seguinte mensagem no navegador: "Itworks". Para executar as aplicações referidas é necessário ajustar as configurações.

0 arquivo "httpd.conf” é responsável pela configuração principal do Apache HTTP Server e contém diretivas de configuração que dão instruções ao servidor web. A configuração do Apache está presente no ficheiro "httpd.conf”, na pasta "conf” do Apache. Ao editá-lo e gravá-lo, deve-se reiniciar o servidor do Apache para que as alterações entrem em vigor. A seguir, apresentam-se as configurações do servidor.

\section{a) Configuração 1: ficheiro httpd.conf}

O parâmetro ServerRoot corresponde ao topo da árvore de diretórios onde são mantidas, e.g., configurações do servidor, erros, ficheiros de log. Cabe ressaltar que na experiência aqui descrita foi utilizado um disco SSD para usufruir de suas características como a velocidade. Assim, foi indicado o ServerRoot como "c:/Apache24". A seguir, é necessário indicar onde será executado o servidor Apache, i.e., por meio de qual endereço IP e portas específicas, em vez dos valores por omissão.

As diretivas desta seção configuram os valores usados pelo servidor, respondendo a qualquer pedido que não seja controlado pela definição <VirtualHost>. É também importante salientar que existe um arquivo extra denominado httpd-vhosts.conf, responsável pelas configurações de múltiplos domínios/hostnames no servidor. No caso exposto, utilizou-se os "VirtualHostcontainers" e o valor por omissão inerente à porta http (80), ou seja, Listen 80. 


\section{b) Configuração 2: ficheiro httpd-vhosts.conf}

Como já foi referido, utilizou-se múltiplos domínios/hostnames no servidor, configurando os "VirtuaIHostcontainers". Para tal, é necessário alterar o arquivo httpd-vhosts.conf, conforme o quadro a seguir.

\section{Quadro 2 - Ficheiro httpd-vhosts.conf do WS-SERVER01 da Escola}

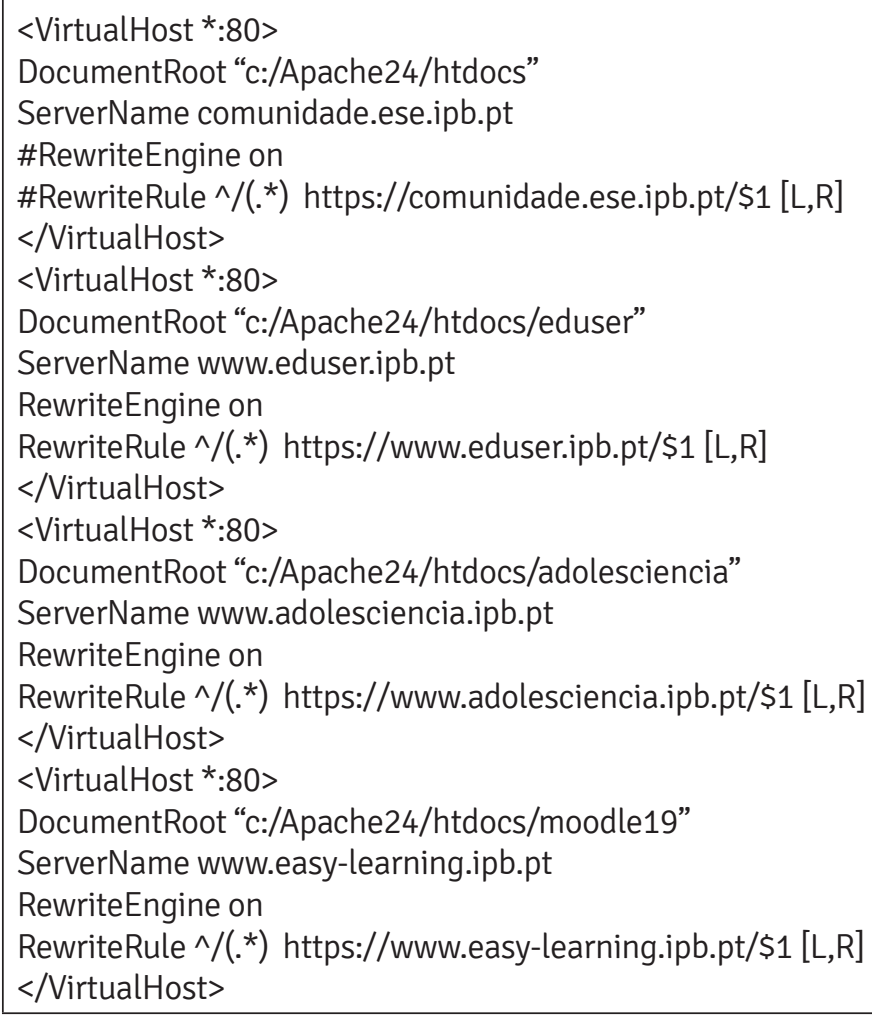

O primeiro passo é ativar a diretiva Virtual hosts, retirando o símbolo cardinal (“\#”) do início da linha: Includeconf/extra/httpd-vhosts.conf. A diretiva ServerName fornece o nome e a porta que o servidor usa para se identificar. Caso não exista registo DNS, deve-se usar o IP do servidor. Por exemplo: ServerName localhost:80 ou ServerName 193.136.194.191:80 (ou: comunidade.ese.ipb.pt:80). As configurações do arquivo C:\Apache24\conflextra\httpd-vhosts.conf podem ser visualizadas no Quadro 2.

\section{c) Configuração 3: ficheiro httpd.conf > módulo rewrite}

Para mapear URLs para caminhos físicos é necessário ativar o módulo mod_rewrite no Apache: LoadModulerewrite_module modules/mod_rewrite.so. 0 módulo mod_rewrite usa um motor de reescrita "rule-based", baseado num parser de expressões regulares (PCRE regular-expressionparser) 
para reescrever URLs pedidos (requestedURLs). Por omissão, o mod_rewrite mapeia um URL para um caminho físico no servidor. Além disso, também pode ser usado para redirecionar um URL para outro.

\section{d) Configuração 4: ficheiro httpd.conf > módulo PHP}

Uma vez que as plataformas alojadas se baseiam em PHP, torna-se necessário adicionar o Módulo PHP - Handler no Apache.

LoadModule php5_module "c: \php\php5apache2_4.dll”

AddHandler application/x-httpd-php .php

PHPIniDir "C: \php”

Directorylndex: Define os tipos de ficheiro que o Apache pode executar por omissão.

Neste caso, necessitamos adicionar os arquivos PHP neste módulo:

$<\mid$ f Modulemod_dir.c $>$

Directorylndex index.html

$</$ IfModule>

Portanto, logo a seguir ao “index.html”, adicionamos, por exemplo: index.php default.php main.php.

\section{e) Configuração 5: pasta pública no servidor web}

As páginas ficam por omissão na pasta "htdocs" já existente na instalação do Apache. A saber: "C:I Apache24\htdocs".

\section{f) Configuração 6: ficheiro httpd.conf > ligações seguras}

Por questões óbvias de segurança utilizou-se um certificado digital como forma de proteger os acessos e a troca de dados. Para ativar a diretiva Secure - SSL/TLS connections, foi utilizado o LoadModulessl_module modules/mod_ssl.so

\section{g) Configuração 7: certificado digital - criptografia}

Foi emitido, considerando que a instituição possui certificados digitais fornecidos por entidades credenciadas um arquivo do certificado: www.easy-learning.ipb.pt.crt. Ressalta-se que a versão instalada do servidor Apache inclui o Toolkit OpenSSL (OpenSSL/1.0.2g), o que permite implementar os protocolos Secure Sockets Layer (SSL v2/v3) e Transport Layer Security (TLS v1).

Para gerar uma chave primária (privatekey) foi utilizada a aplicação OpenSSL. Para isso, é necessário abrir uma janela de comando DOS e acessar o diretório apache24/bin, onde OpenSSL.exe está armazenado, e digitar: openssl>genrsa -des3 -out server.key 1024. É necessário, ainda, indicar uma palavra de passe, quando esta for solicitada. Finalmente, os arquivos dos certificados (www.easy-learning.ipb.pt.crt, trust-chain.crt, www.easy-learning.ipb.pt.key) foram copiados para a pasta C:\Apache24\conf\ssl.crt.

\section{h) Configuração 8: Configuração de https (AcceptFilterhttpsnone)}

Esta diretiva oferece otimizações específicas ao nível de servidor para um socket à escuta por um tipo de protocolo. A premissa básica é para que o Kernel não envie um socket para o servidor proces- 
sar até que dados sejam recebidos ou um pedido HTTP (HTTP REQUEST). Em vez disso, são mantidos em Buffer. De acordo com a documentação do Apache, os valores por omissão para o Windows são: AcceptFilterhttp data e AcceptFilterhttps data.

Ao utilizar o valor none, accept () é utilizado em vez de AcceptEx () e, dessa forma, os sockets não são reciclados entre conexões. Essa configuração foi necessária, uma vez que o Apache não estava servindo devidamente as páginas https.

\section{i) Configuração 9: configuração do httpd-ssl}

A configuração dos Virtual Hosts que utilizarão o certificado SSL deve ser realizada no arquivo C:I Apache24 \conf \extra\Httpd-ssl.conf. O Quadro 3 ilustra a configuração do HTTPD-SSL. Cabe salientar que a porta utilizada pelo protocolo SSL é a 443 e que foi indicada a localização dos arquivos do certificado e da privatekey:

SSLCertificateFileconf/ssl.crt/trust-chain.crt

SSLCertificateKeyFileconf/ssl.crt/www.easy-learning.ipb.pt.key

Quadro 3 - Configuração do arquivo httpd-ssl.conf do WS-SERVER01

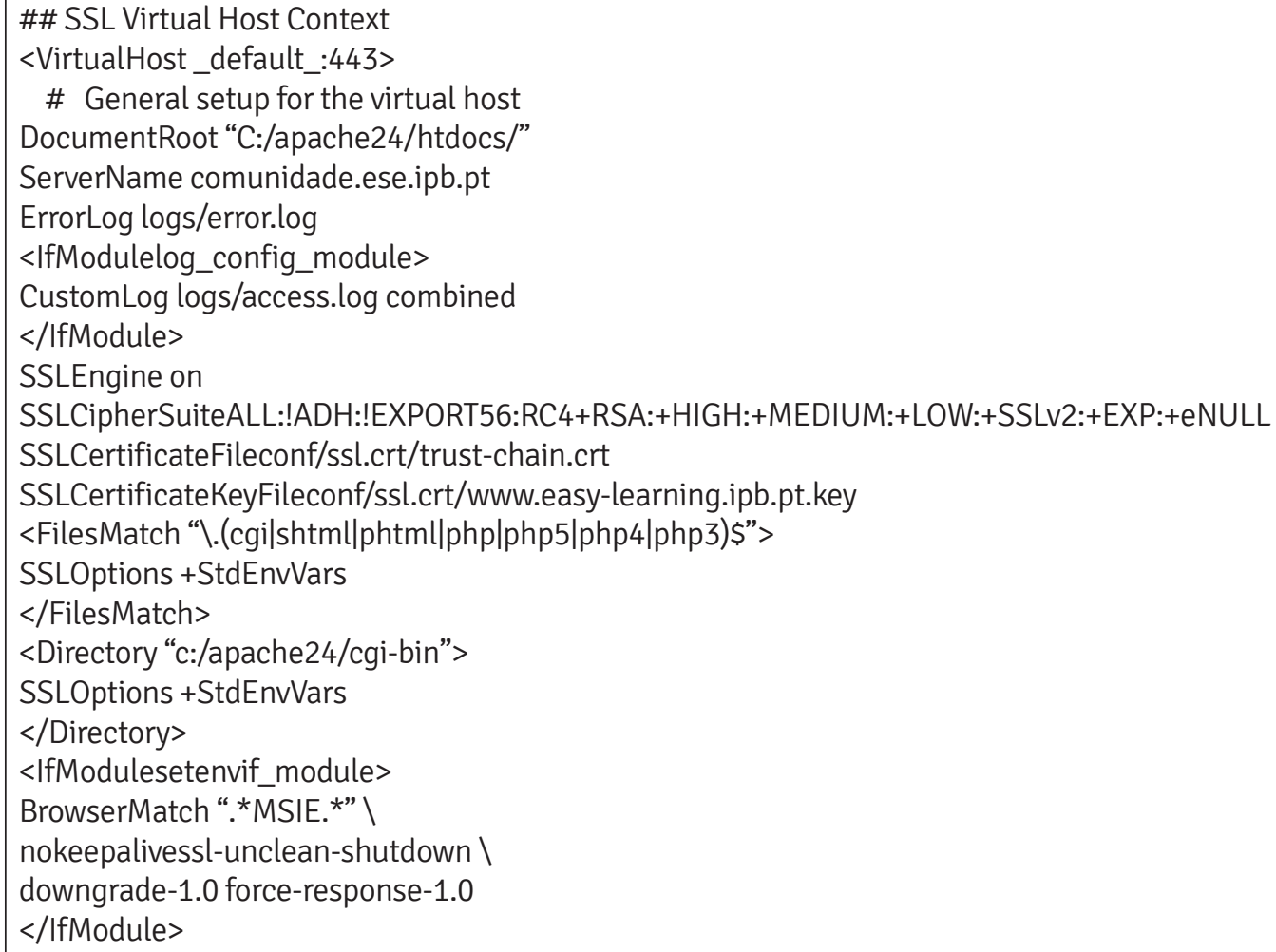


Finalmente, é necessário copiar as respectivas pastas de cada plataforma/aplicação/website para a pasta "C:\Apache2.4\htdocs". Genericamente, as configurações referidas corresponderam as mais importantes e das quais dependiam as aplicações para serem devidamente executadas pelo servidor web.

\subsubsection{INSTALAÇÃO E CONFIGURAÇ̃̃O DO PHP/5.6.19}

Após fazer download (http://windows.php.net/download/\#php-5.6-nts-VC11-x86) deve-se extrair o PHP na pasta C: \php. Ainda em c: \php, renomeamos o ficheiro "php.ini-dist" para "php.ini”. Neste arquivo constam as configurações a seguir.

\section{a) Configuração 1: ativar extensões}

extension_dir = “./"

Busca-se a linha extension_dir = ". /" e a altera para extension_dir = "c:/php5/ext/", já que esta pasta corresponde ao diretório onde constam as extensões do PHP (MySQL, Curl, GD, etc). Uma vez que é necessário realizar conexões com bases de dados MySQL, a partir do PHP, deve-se ativar a extensão correspondente, retirando “;” do início da linha "extension=php_mysql.dll”.

\section{b) Configuração 2: ativar linguagem PHP}

Para poder usar o motor da linguagem de scripting PHP no Apache é necessário garantir que “engine $=0 n$ ".

\section{c) Configuração 3: visualização de erros e avisos}

A diretiva Error handling/Tratamento de erros indica ao PHP a forma como os erros e avisos são tratados. Como exemplo, a seguinte configuração mostra todos os erros, exceto para avisos e avisos de codificação standards: error_reporting = E_ALL \& $\sim$ E_DEPRECATED \& $\sim$ E_STRICT. 0 output de erros é bastante útil na fase de desenvolvimento, ou mesmo no caso em pauta, para verificar a existência de problemas de compatibilidade com as versões atualizadas do Apache, PHP e MySQL. Por óbvio, em modo produção, deve-se optar por não mostrar qualquer tipo de erro, sejam de código obsoleto ou avisos. A diretiva display_errors indica a intenção de mostrar os erros ou não. Dependendo do código usado na aplicação, a informação sensível poderá ser mostrada indevidamente, e.g., passwords e usernames. Em modo produção aconselha-se o uso de arquivos de logs. Assim, a configuração da diretiva deve ser: display_errors = Off

\section{d) Configuração 4: ativar UTF-8}

O UTF-8 (8-bit Unicode Transformation Format) é um tipo de codificação Unicode de comprimento variável (UNICODE, 2017). Ele pode representar qualquer caractere universal padrão do Unicode, sendo também compatível com o ASCII (ASCII, 2017). Por esta razão, na experiência aqui descrita, foi adaptado um tipo de codificação padrão para e-mail, páginas web e outros locais onde os caracteres são armazenados. Por omissão, no PHP está definido para UTF-8 Diretiva default_charset = “UTF-8”. 


\section{e) Configuração 5: dificuldades de migração/riscos/consequências}

Devido à urgência de algumas plataformas estarem disponíveis aos utilizadores foi necessário disponibilizar, temporariamente, as versões desatualizadas das plataformas. Disso resultaram alguns problemas relacionados a incompatibilidades ao nível do código PHP. Na versão anterior das plataformas (por exemplo: OJS eduser e OJS adolesCiência) ainda era utilizada a extensão "php_mysql. dll”. Contudo, essa extensão foi descontinuada (PHP, 2017b). No entanto, as aplicações, ao usarem bases de dados, necessitavam dessa extensão. Para solucionar esse problema, foi necessário ativar a seguinte extensão no PhP: extension=php_mysqli.dll, conforme Quadro 4.

Quadro 4 - Substituição da extensão php_mysql.dll pela php_mysqli.dll

\# Código usando extensão php_mysql.dll

\$link = mysql_connect('localhost', 'user', 'password');

mysql_select_db('dbname', \$link);

\# Código usando extensão php_mysqli.dll

\$link = mysqli_connect('localhost', 'user', 'password', 'dbname');

Fonte: Elaborado pelos autores (2017).

O Quadro 5 exemplifica as alterações realizadas no código (substituição da extensão "php_mysdl. dll”) pela extensão "php_mysqli.dll”. Por conseguinte, a execução de consulta foi também alterada.

Quadro 5 - Substituição nas queries ao alterar de php_mysql.dll para php_mysqli.dll

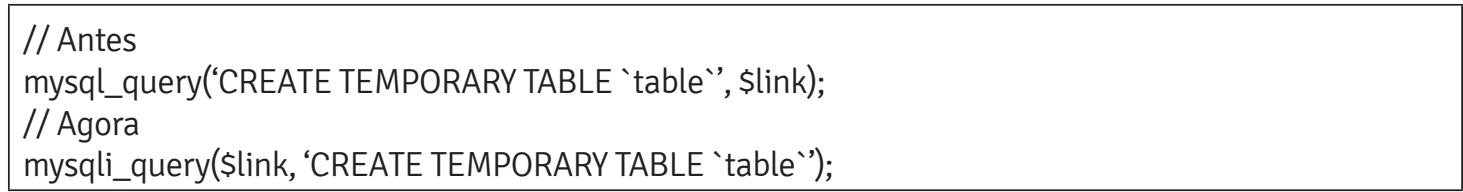

\section{f) Configuração 6: outras alterações}

É necessária a indicação da porta onde será escutada a base de dados: mysqli.default_port = 3306. Deve, também, ser ativada a extensão necessária para fazer uso do SSL, a saber: extension=php_openssl.dll.

\subsubsection{INSTALAÇÃO E CONFIGURAÇÃO DO MYSQL 5.7}

Um dos mais populares Sistemas Gerenciadores de Banco de Dados (SGBD) que é suportado por uma ativa comunidade de programadores é o MySQL. Para utilizá-lo deve-se fazer o download do pacote de software em http://dev.mysql.com/downloads/mysql/. Com intuito de possuir um ambiente com ferramentas integradas, utiliza-se, também, o MySQL Workbench, o qual permite (WORKBENCH, 2017):

a) modelagem e desenho de bases de dados

b) desenvolvimento de sql

c) administração de bases de dados 
d) migração de bases de dados

As configurações apresentadas seguir foram efetuadas no arquivo My.ini em C:|ProgramDatal MySQLIMySQL Server 5.7

\section{a) Configuração 1: credenciais do administrador e porta}

Após a instalação é necessário definir o usuário e senha para o administrador do SGBD. Posteriormente, deve ser também indicada a porta pela qual será realizada a comunicação, como por exemplo: port=3306.

\section{b) Configuração 2: ativar UTF-8}

Para definir um conjunto de caracteres padrão foi utilizada a configuração: default-character-set=utf8.

\section{c) Configuração 3: mecanismo de armazenamento}

O InnoDB é, por omissão, no MySQL 5.7, o mecanismo padrão de armazenamento. Em termos gerais, optou-se por esse mecanismo devido às vantagens ao nível da performance e alta confiabilidade (INNODB, 2017a). Ou seja, utilizou-se a diretiva: default-storage-engine=INNODB. Contudo, ocorreram problemas de performance, uma vez que o acesso à base de dados se mostrou lento. Assim, procedeu-se a seguinte alteração:

Antes: innodb_flush_log_at_trx_commit = 1

Depois: innodb_flush_log_at_trx_commit $=2$

\section{d) Configuração 4: outras funcionalidades}

De acordo com a especificidade do servidor web, outras configurações relacionadas à performance do MySQL devem ser realizadas. Por exemplo, foi desativada a diretiva do Windows Hosts file para IPv6, bastando acrescentar o símbolo "\#” no arquivo hosts C:|Windows\System32\Drivers\etc): \#::1 localhost.

Ainda é aconselhável alterar também o tamanho do Database Buffer Size de 1/4 ou 1/2 da RAM do servidor. Para tabelas InnoDB, aplicadas no caso abordado, tem-se 4GB de RAM, ficará 1024 MB, ou seja: innodb_buffer_pool_size $=1024 \mathrm{M}$. 0 valor de innodb_log_file_size deverá ser $1 / 4$ do valor de innodb_buffer_pool_size, ou seja: innodb_log_file_size $=256 \mathrm{M}$.

\section{CONSIDERAÇÕES FINAIS}

O projeto descrito apresentou a disponibilização de plataformas e aplicações web online, devidamente atualizadas numa escola superior, garantindo a segurança requerida num ambiente acadêmico. Para tal, procedeu-se o desenvolvimento do projeto de recuperação do servidor de aplicações, relatado em duas fases: a) instalação e configuração do servidor web Apache, instalação e configuração do Sistema de Gestão de Base de Dados MySQL e instalação e configuração da Linguagem de programação PHP; b) instalação das plataformas OJS e Moodle, entre outras aplicações educativas de interesse para a comunidade educativa. 
A reinstalação do servidor não só restabeleceu os níveis de segurança necessários, como também a atualização para as versões mais recentes das plataformas open source utilizadas. Como principal desvantagem identificou-se a arquitetura física da máquina, uma vez que o equipamento não poderia ser atualizado. 0 projeto permitiu, ainda, constatar que o processo de migração requer testes e adaptações de ambientes já em funcionamento. Considera-se esse mais um importante resultado da experiência descrita, constituindo um aprendizado para futuros trabalhos.

A descrição do processo de instalação e configuração de softwares, por mais árduo que seja, constitui uma ação fundamental para a documentação, atualização e manutenção de ambientes tecnológicos. Essa prática viabiliza a replicação por outros usuários, a partir de experiências de sucesso, o que colabora para a qualidade da gestão em tecnologia. Dessa forma, intenta-se que os resultados do estudo se tornem úteis à comunidade acadêmica e técnica.

\section{REFERÊNCIAS}

A guide to the project management body of knowledge (PMBOK guide). Newtown Square, Pa: Project Management Institute, 2004.

Apache Core Features. Disponível em: http://httpd.apache.org/docs/current/mod/core.html. Acesso em: 10 maio 2017.

Apache Module mod_rewrite. Disponível em: http://httpd.apache.org/docs/current/mod/mod_ rewrite.html. Acesso em: 10 maio 2017.

ASCII - American Standard Code for Information Interchange. ASA standard X3. 4,1963. Disponível em: http://www.worldpowersystems.com/J/codes/X3.4-1963/. Acesso em: 12 maio 2017.

Description of core php.ini directives: default_charsetstring. Disponível em: http://php.net/ manual/en/ini.core.php\#ini.default-charset. Acesso em: 14 maio 2017.

Download MySQL Workbench. Disponível em: http://dev.mysql.com/downloads/workbench/. Acesso em: 16 maio 2017.

Downloading Apache for Windows. Disponível em: http://www.apache.org/dist/httpd/binaries/ win32/. Acesso em: 10 maio 2017.

DRESCH, Aline; LACERDA, Daniel Pacheco; ANTUNES JÚNIOR, José Antônio Valle. Design science research: método de pesquisa para avanço da ciência e tecnologia. Porto Alegre: Bookman, 2015. 
InnoDB Startup Options and System Variables. Disponivel em: http://dev.mysql.com/doc/refman/5.7/ en/innodb-parameters.html\#sysvar_innodb_flush_log_at_trx_commit. Acesso em: 18 maio 2017.

JUNIOR, João Batista Bottentuit; COUTINHO, Clara; ALEXANDRE, Dulclerci Sternadt. M-Learning e Webquests: as novas tecnologias como recurso pedagógico. Disponível em: http://www.br-ie.org/ pub/index.php/sbie/article/viewFile/543/529. Acesso em: 9 ago. 2018.

\section{MAIA, Marta C. 0 uso da tecnologia de informação para a educação a distância no ensino} superior. São Paulo: FGV-EAESP, 2003. p. 294.

MORAIS, Nídia Salomé; POMBO, Lúcia; BATISTA, João; MOREIRA, António; RAMOS, Fernando. Uma revisão de literatura sobre o uso das tecnologias da comunicação no ensino superior. Disponível em: http://pentaho.letras.up.pt/ojs/index.php/prismacom/article/view/1884. Acesso em: 9 ago. 2018.

Overview. Disponível em: http://php.net/manual/en/mysqli.overview.php. Acesso em: 14 maio 2017.

RCTS CERT - Segurança. Disponível em: https://www.fccn.pt/seguranca/rcts-cert/. Acesso em: 8 abr. 2017.

The InnoDB Storage Engine: MySQL Documentation. Disponível em: http://dev.mysql.com/doc/ refman/5.7/en/innodb-storage-engine.html. Acesso em: 18 maio 2017.

What is Unicode? The unicode consortium. Disponivel em: http://www.unicode.org. Acesso em: 12 maio 2017. 
Recebido em: 30 de Março de 2018

Avaliado em: 5 de Maio de 2018

Aceito em: 10 de Agosto de 2018

1 Doutor em Engenharia Eletrotécnica e de Computadores - Universidade do Porto, Professor Adjunto do Instituto Politécnico de Bragança, Portugal. E-mail:vg@ipb.pt

2 Instituto Politécnico de Bragança, Portugal.

E-mail: roger@ipb.pt

3 Graduada em Ciências da Computação - Unit, Mestranda em Ciências da Computação - Universidade Federal de Sergipe (UFS), Brasil. E-mail: santoslay3@gmail.com

\section{四四

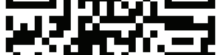

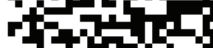

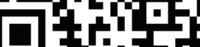

A autenticidade desse artigo pode ser conferida no site https://periodicos. set.edu.br

\section{(2) (1) (2)}

Este artigo é licenciado na modalidade acesso abertosob a Atribuição-Compartilhalgual CC BY-SA

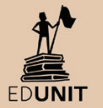

